\title{
Application of airborne magnetic survey and geoelectric methods for identification and characterization of mineralized gold zones in the Príncipe, TO
}

\author{
Pachêco, IA (IG-UnB); Pinto, VPP (IG-UnB); Borges, WR (IG-UnB)
}

Copyright 2019, SBGf - Sociedade Brasileira de Geofísica

This paper was prepared for presentation during the $16^{\text {th }}$ International Congress of the Brazilian Geophysical Society held in Rio de Janeiro, Brazil, 19-22 August 2019.

Contents of this paper were reviewed by the Technical Committee of the $16^{\text {th }}$ International Congress of the Brazilian Geophysical Society and do not necessarily represent any position of the SBGf, its officers or members. Electronic reproduction or storage of any part of this paper for commercial purposes without the witten consent of the Brazilian Geophysical Society is prohibited.

\begin{abstract}
Although the Príncipe Gold Deposit attracted economic interest since the gold cycle in 1724, there are no reports of publications regarding to near-surface geophysics studies in the area. Besides that, the region's real economic viability is still neglected since few large mining companies operate in the northern part of the Principe granite. Therefore, this paper seeks to discuss the airborne magnetic survey use for detail local structures. In addition, it reports the use of geoelectrical data for subsurface models and the research has as objective the identification of probable mineralized zones The Príncipe Gold Deposit is orogenic and it is known as a pressure shadow zone that acted as structural traps for the ore (Corrêa et. al., 2015). Then, two profiles with resistivity and IP data for two lines were conducted perpendicularly to the main structural trend $\mathrm{N} 10^{\circ} \mathrm{W}-\mathrm{N} 20^{\circ} \mathrm{E}$, with 10 meters spacing between electrodes. Granite with intense deformation was interpreted as more resistive zones (1000-4000 ohm.m), shear zones with approximately 670 ohm.m and mineralized zones were interpreted as greater than $14 \mathrm{mV} / \mathrm{V}$ values.
\end{abstract}

\section{Introduction}

High gold concentrations are found in the study area due to the intense hydrothermal alterations, in a region named by Oliveira (2012) as hydrothermalite. This unit has been the source of studies focusing on the local auriferous genesis (e.g., Correa et. al., 2015; Sousa et. al., 2015). These studies have shown that this particular formation is associated with strike-slip movement and relief zones. Correa (2015) explains that due to the shear strength, the Príncipe granite behaves as a porphyroclast in regional scale for the migration of hydrothermal fluids. Therefore, two pressure shadows in the NS extremes of the granite act like structural traps for the ore, one of them being the hydrothermalite, in the northern part. In the pressure relief zones, the fluid-rock interaction increases and forms a discontinuous system of quartz-carbonate-sulfide-goldveins, interconnecting with shearing zones facing the $\mathrm{N}$ $\mathrm{N} 20^{\circ} \mathrm{E}$ direction. Despite the use of airborne geophysics for mapping purposes in past studies, geophysics shallow reports in the region have not been disseminated. Thus, this study aims to detail the internal architecture of the unit represented by the intense hydrothermal alteration of the Príncipe granite by means of airborne magnetic survey to detail the lineaments and geoelectrical methods of resistivity and time-domain induced polarization to detail de near surface. Additionally, it aims to determine the average depth of the basement and the anomalous quantified behavior with regards to the electrical properties of the possible mineralized zones.

\section{Method}

One of the first instruments to be used from magnetic susceptibility was the compass and one of the earliest records has come from Chinese navigators who have manipulated it since the 10th century; however, this physical property was often used as a subsurface research tool only during the second industrial revolution. The peak of the research began during World War II due to the need to detect submarines; consequently, the first fluxgate magnetometers coupled to aircraft were manufactured.

Today, great part of the airborne magnetic surveys method is applied to geological mapping and mineral exploration. Therefore, the results were compared with the anomalous lineaments correlated to shear zones and limits of tectonic domains of the study region. The processed data are from Tocantins project (1073), and they are a courtesy of the Ministry of Mines and Energy (MME), Oil National Agency and the Mineral Resources Research Company (CPRM), since the latter was responsible for the product of the Anomalous Magnetic Field (AMF). The flowchart with such products can be seen in figure 1 and they are (a) AMF, (b) Horizontal derivative in the $\mathrm{x}$ direction $(\mathrm{dx})$, (c) Horizontal derivative in the $y$ direction $(d y), d)$ the Vertical derivative $(d z),(e)$ Horizontal Gradient Amplitude (HGA), (f) Analytical Signal Amplitude (ASA) and (g) Tilt Derivative (TDR).

In 1912, Conrad Schlumberger approached, for the first time, the electrical method applied as active technique, where the Earth is energized by an external source and the difference in voltage output is measured. New methods have since been implemented and used in the superior shallow crust, such as the Induced Polarization (IP). Time-domain (TD) induced polarization method measures voltage decay after it reaches an overvoltage, this process is executed with the interruption of the current. Consequently, the chargeability values can be 
stipulated and it is used mainly in studies of disseminated metallic minerals deposits.

The highest gold concentrations in the Príncipe orogenic deposit are found on the primary mineralization, mainly disseminated in quartz veins, subsequently interrupted by faults and alterations, as well as disseminated in the Príncipe granite. The ambiguity of the method used in this context is due the fact that anomalies can also be associated to $\mathrm{Cu}-\mathrm{Fe}$ sulfides, magnetite and silicate alterations.

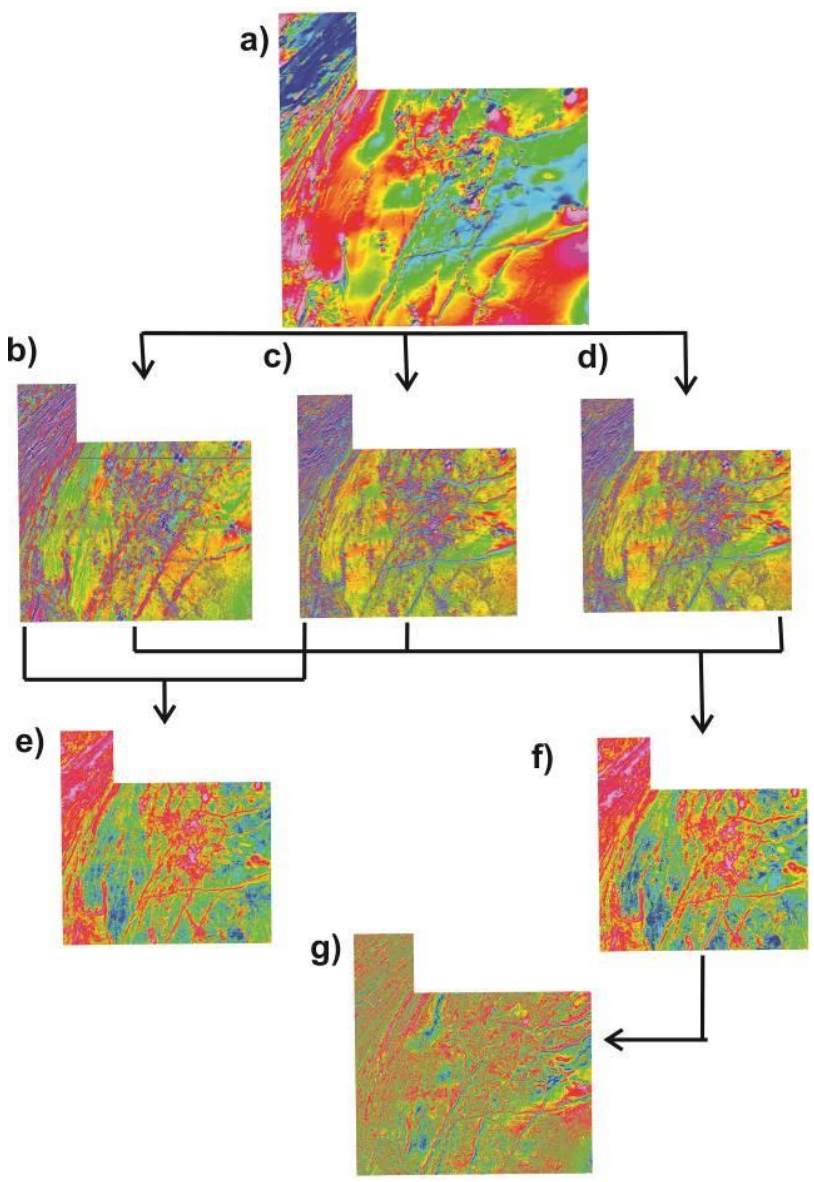

Figure 1: Flowchart with the following products: (a) AMF, (b) Horizontal derivative in the $x$ direction $(d x)$, (c) Horizontal derivative in the $y$ direction (dy), (d) the Vertical derivative (dz), (e) Horizontal Gradient Amplitude (HGA), (f) Analytical Signal Amplitude (ASA) and $(g)$ Tilt Derivative (TDR).

Resistivity and Chargeability acquisitions were executed along two lines positioned in a way that they did not remain parallel to the lineaments (Figure 2). Additionally, the image shows the local geology, as proposed in the Final Graduation Thesis by the University of Brasília in 2012. The Syscal Pro instrument, from Iris Instruments, was used for the measurements, with 490 and 440 meters for the first and second lines, respectively, both positioned in the SE-NW direction.
The choice of the inversion method and parameters depends on factors such as: local geology, amount of data, appropriate inversion time, resistivity contrast and data noise. Thus, some tests were done with different inversion parameters in order to analyze their influence on the results. Robust inversion was used, because this option highlights vertical bodies, hence, it emphasizes the mineralized veins. Fine mesh refinement was executed, with a vertical to horizontal flatness filter ratio of 2; the size of the cell used was equal to half the spacing between the electrodes, therefore, the unit is represented as 5 meters, however the real electrode spacing is $10 \mathrm{~m}$; the thickness for the first layer of blocks was 0,3 times the distance between the electrodes; the Jacobian matrix was recalculated for all interactions; in order to generate the model, Gauss-Newton method was conducted as a way to solve the equations of the least squares inversion, and, lastly, the resistivity profile was expressed in logarithm and the chargeability in linear form.

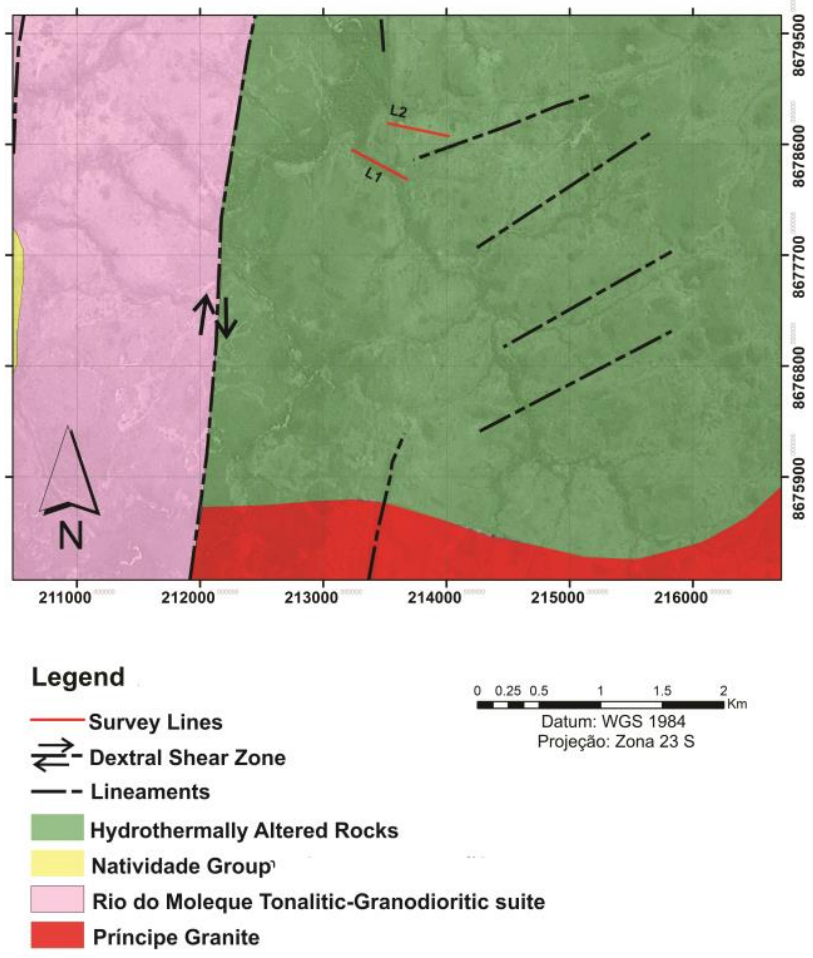

Figura 2: Location of acquisition lines, as well as the geological units of the region and the structural lineaments.

\section{Results}

Figure 3 illustrate Analytical Signal Amplitude, it is possible observe different domains for ASA. From this signal it is possible to delimit the geological contacts and shear zones. The Magmatic Arc of Goias is positioned in 
a group that presents the highest values of $n T / m$, and the maximum values, positioned in the northwest of the map, are related to the Transbrasilian Lineament. The Goiás massif is between two zones of shear, with values between high and medium. The Cavalcante Arrais and Almas Conceição do Tocantins domains are part of the Natividade-Cavalcante block and were divided in two, by $\mathrm{Nd}$ isotopes studies (Fuck (2014).) Both blocks present notable difference in ASA, the first is predominantly low with little variations between average and high; on the other hand, the second is dominated by high and average values. Lastly, the Bambuí do Cráton group is located in the eastern part of the map, with low signal amplitude.

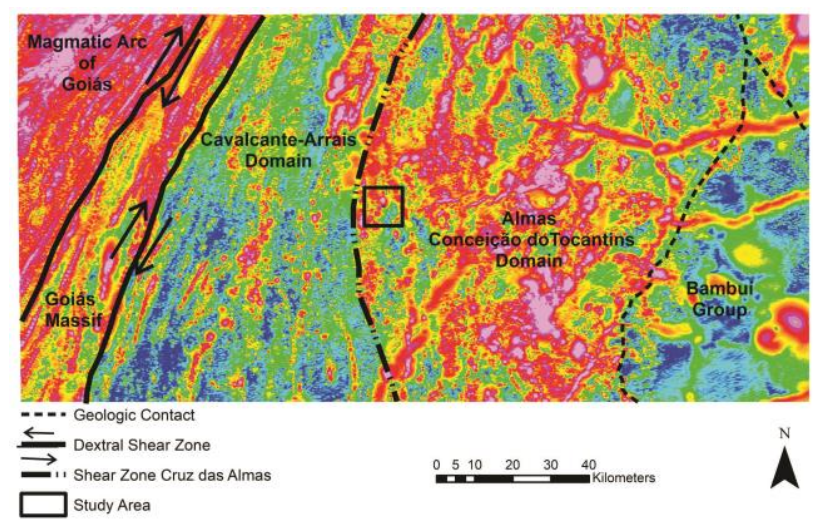

Figura 3: Representation of ASA and the distinction of Magmatic Arc of Goiás, Goiás massif, Cavalcante-Arrais domain, Almas Conceição do Tocantins domain, Bambuí group, dextral shear zone and Cruz de Almas shear zone.

The results of the vertical derivative $d z$ and Tilt derivative showed that the two lines of resistivity and induced polarization were positioned on a high magnetic field. The high anomaly, related to the local lineaments, demonstrates the NS tendency of the shear zones (figure 4 (a) and (b)). Besides that, both demonstrate that the local faults have NS trend and it is clearer observe the $\mathrm{N} 45^{\circ} \mathrm{E}$ fault trend from the vertical derivative product.

In the resistivity profile for line 1 (figure 5-a), the highest resistivity were larger than 5500 ohm.m. For the chargeability profile, three main anomalies were observed, which can be seen in the second profile (figure 5-b). For IP products, the voltage decay curves were taken into consideration for the filtration process. The third profile (figure 5-c) was filtered in detail, since less data was excluded, with the purpose of maintaining the larger values of the first anomaly; in addition, the color scale was adjusted in order to observe the gradient behavior of the anomalies and centralize them. The anomalous chargeability values for the first line were considered low, between 12 and $14 \mathrm{mV} / \mathrm{V}$. Anomaly 1 was considered quite extensive, however its gradient increases with depth, which can be an indication of increased mineralization with depth. After the second filtering and color scale adjustment, profile 3 (fig. 5-c) confirms that the values for anomaly 1 increase with depth and vary, from 31 to $37 \mathrm{mV} / \mathrm{V}$, in depths greater than 20 meters. Anomalies two and three, on the other hand, were fairly superficial, with intermediate values, and with the chargeability variation decreasing with depth, however the last anomaly was considered more intense than the second one.

The second line is positioned farther Northwest than the first (figure 6-a), and its resistivity values are similar to the first line: the highest values are equal to 4500 ohm.m. The chargeability for this line had a behavior of higher values, correlating with the anomaly 1 of the first line. In section two (figure $6-b$ ) it is possible to observe that the values are higher than $28 \mathrm{mV} / \mathrm{V}$ for anomalies 1, 2 and 4, while anomaly 3 was assessed as low and of the same type as anomalies 2 and 3 for line 1 .

It is possible to confirm this behavior on the third inversion (figure 3-c), with the first one positioned in an average depth of 15 meters, with initial values of $30 \mathrm{mV} / \mathrm{V}$ and reaching higher values $(40 \mathrm{mV} / \mathrm{V})$ approximately 24 meters below the surface. Anomaly 2 has the top at 10 meters and the higher values (42 mV/V) in depths between 14 and 25 meters. Anomaly 3 is the most superficial, 7 meters, and its maximum value is almost $25 \mathrm{mV} / \mathrm{V}$ in 9,56 meters, decreasing to $19 \mathrm{mV} / \mathrm{V}$ up to 29,7 meters. From anomaly 4 , it is possible to notice a slight SE inclination and is the deepest, since the highest value $(31 \mathrm{mV} / \mathrm{V})$ is found in 24 meters; however, it can be observed that the values increase with depth. 
a)

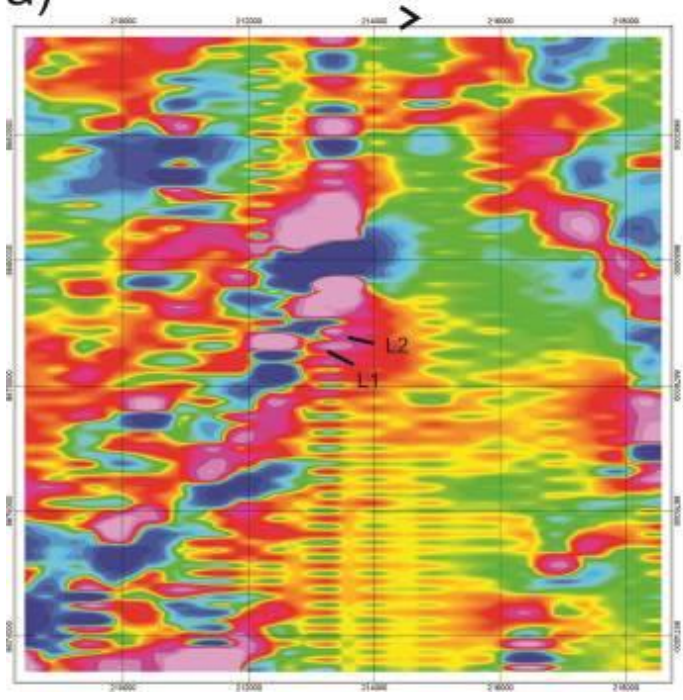

b)

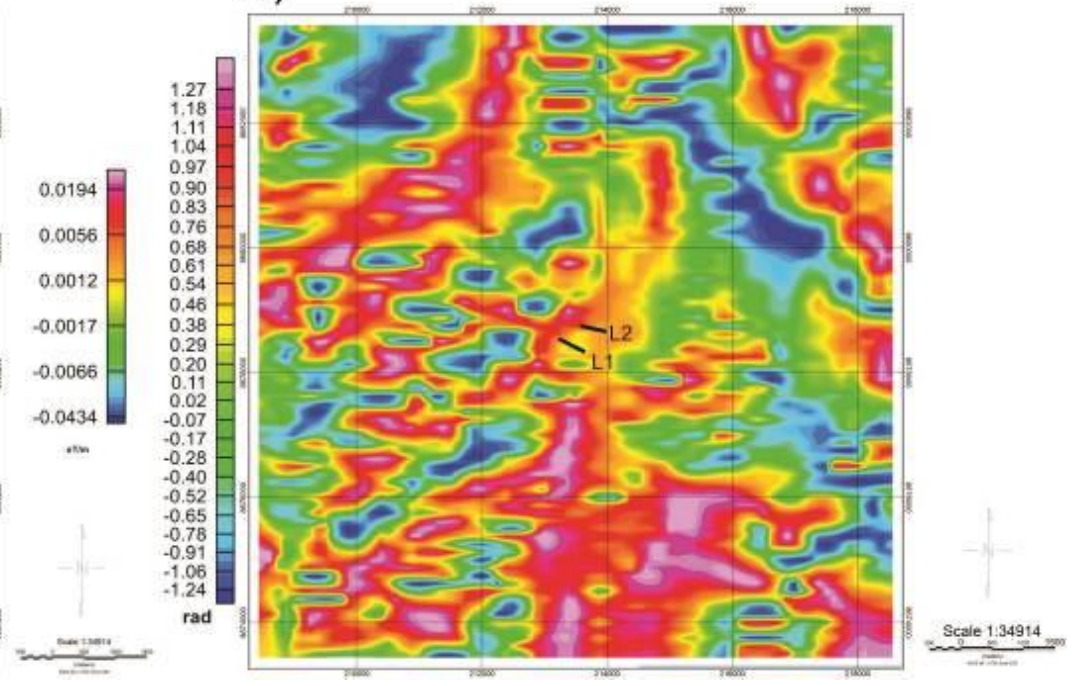

Figure 4: Line 1 and 2 above: a) Vertical Derivative $d z$ and b)Tilt Derivative.

a)

Depth

(m) in 5 Abs. error $=3.7 \% \quad 2000 \quad 1000-1800$.

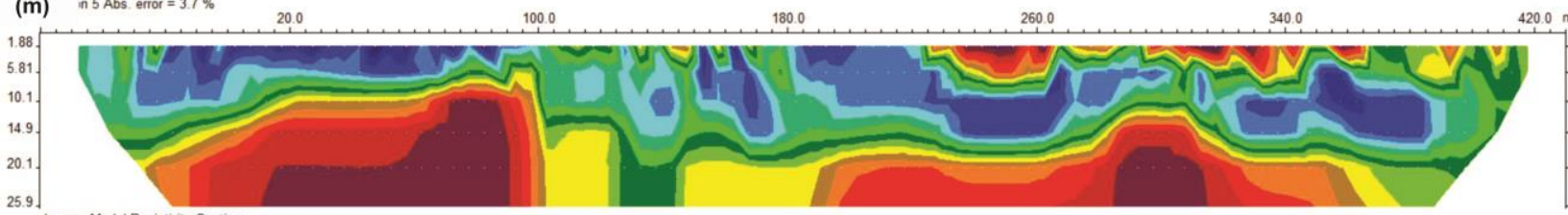

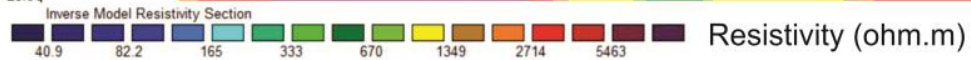

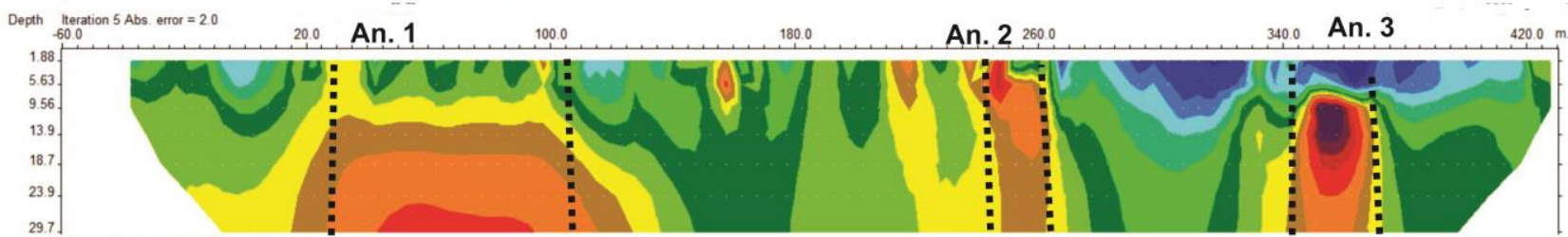

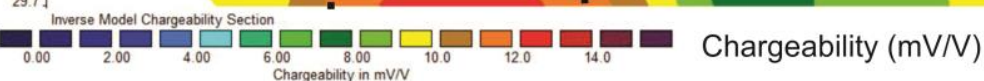

c)

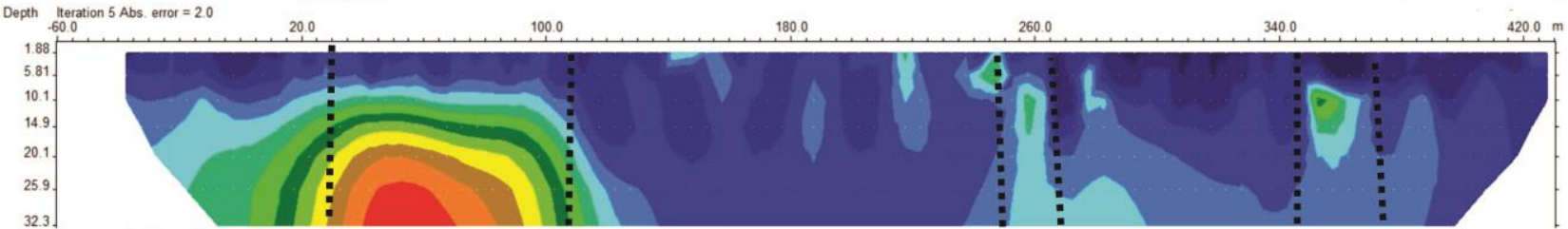

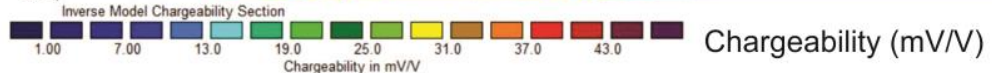

$\mathrm{SE} \longrightarrow \mathrm{NW}$

Figura 5: Geoelectrical sections for Line 1. A) Resistivity; B) Chargeability 1; C) Chargeability 2. 
a)

Depth
[ (m) 3 Abs. error $=3.4 \%$

80.0

240.0

320. 400.0

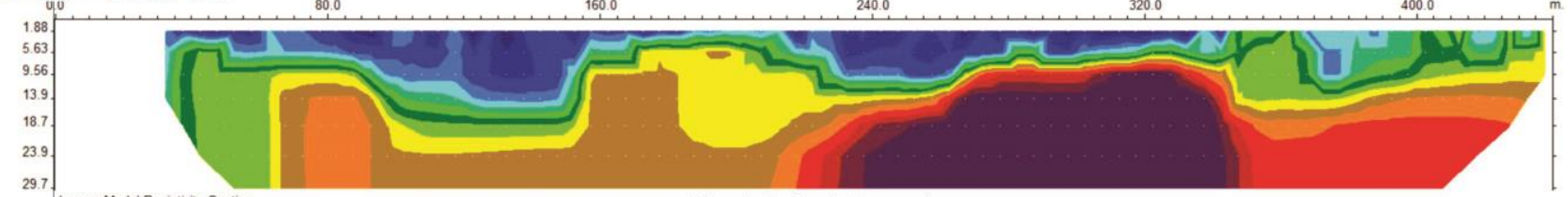

Inverse Model Resistinity Section

Depth Iteration 5 Abs. error $=3.4 \quad$ Resistrity in ohm.m

${ }_{160.0}$ An, 2

An. $3 \stackrel{240.0}{2}$

Unit electrode spacing $5.00 \mathrm{~m}$

)

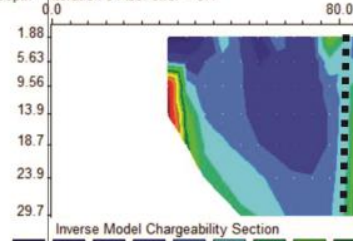

active

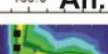

$\stackrel{320.0}{.} \ldots$ An, 4

400.0

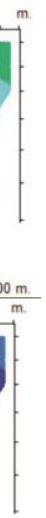

c)
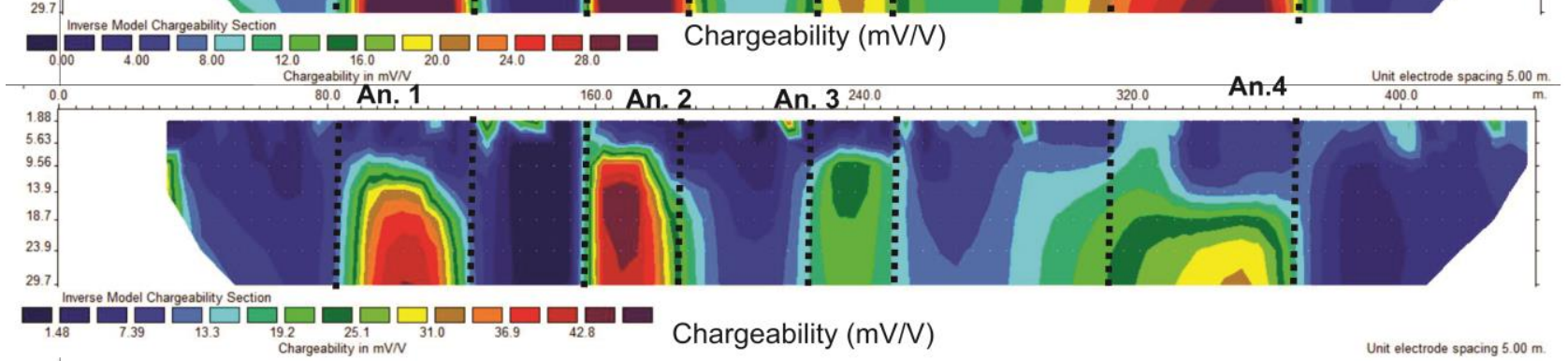

$\mathrm{SE} \longrightarrow \mathrm{NW}$

Figura 6: Section for L2. A) Resistivity, B) Chargeability (model 1), C) Chargeability (model 2).

From the resistivity data, the units sections were displayed into three dimensions for a better visualization of the results (figure 7).

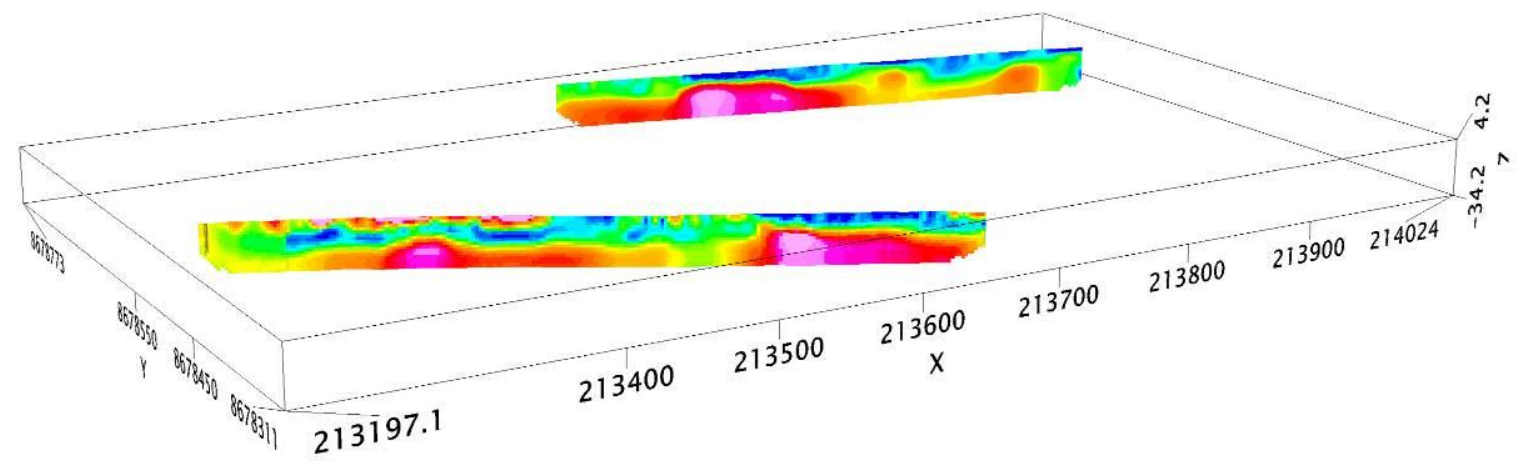

Figura 7: $3 D$ visualization of 2 resistivity sections.

\section{Conclusions}

The highest resistivity values on lines 1 and 2 were considered as the Príncipe granite (larger than 2714 ohm.m), while the resistivity of $331-1200 \mathrm{ohm} . \mathrm{m}$ was interpreted as the shear zone. In line 2, the region adjacent to the granite presented a resistivity varying from 1347 to 1875 ohm.m. The composing material was not interpreted, however, it is believed that it could be the same granite, more fractured or altered.
Chargeability values larger than $30 \mathrm{mV} / \mathrm{V}$ were associated to well mineralized zones, while those between 19 and 28 $\mathrm{mV} / \mathrm{V}$ were associated with weak mineralization zones. It was also observed that the most intense mineralization occurs in greater depths, possibly in quartz veins. The presence of lower gold concentrations next to the surface suggests a weak mineralization, with eluvial or alluvial origins, while higher values are found in primary mineralization. Having made these remarks, the 
geological profiles for each line were represented in Figures 8 and 9.

Queiroz (2001) reported that the age of mineralization by $\mathrm{Rb}-\mathrm{Sr}$ in secondary biotites is $517 \pm 40 \mathrm{Ma}$, demonstrating that the gold emplacement occurred along quartz veins at the final stages of the Brasiliano Cycle, which related to the model hereby proposed. Therefore, four high mineralization zones were proposed, some of them in areas with changes in resistivity, however, they were not identified as vein zones for not having presented a significant change in electric properties and because direct samples was not collected in the depths stipulated.

A trench was made for line 1 , measuring about 5 meters in depth, near the anomaly 1 , with findings of oxidized material, iron oxide and quartz veins with a small concentration of gold. For the second line, a similar trench was made, 5 meters deep, near the second anomaly, with no significant presence of gold in the area.
It is suggested that the highest gold concentrations in the area of research are to be found below 15 meters in depth. However, the methods used do not determine a quantitative analysis of the gold concentration; they present the regions with the highest mineralization, which can be due to the gold and other material such as $\mathrm{Cu}-\mathrm{Fe}$ sulfide, magnetite and hematite. Therefore, it is recommended that deeper holes be made, in order to describe the materials found, perform chemical analyses, acquire petrophysics data such as magnetic susceptibility, texture and interface of the different constituents of the rock.

Although the analysis of the geoelectric and magnetic surveys data have been important to understand the geological issues such as structures, they can be better correlated with more adequate correlation between 3D near surface geophysics, airborne geophysical surveys and field works. Therefore it would be of great importance to the more detailed understanding of the deposit geometry.

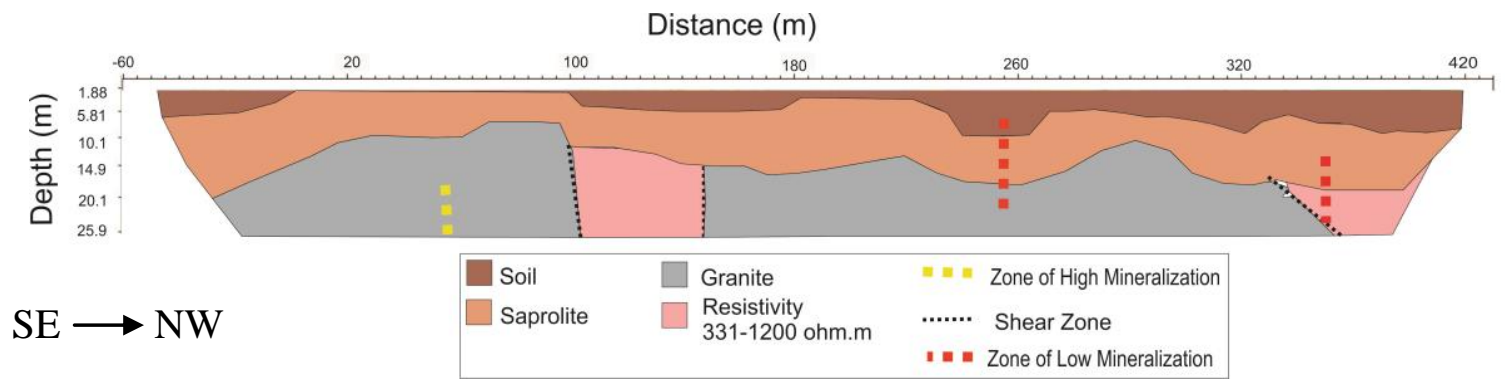

Figure 8: Geological model for $L 1$.

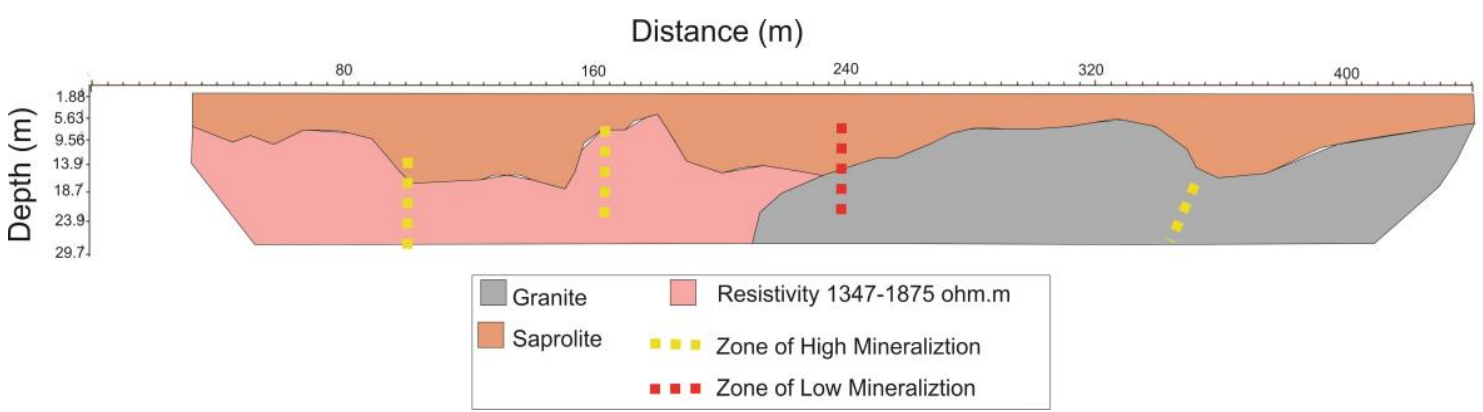

Figure 9: Geological model for linha 2.

\section{Acknowledgements}

Special thanks to JP Mineradora and to the Applied Geophysics Laboratory of the University of Brasília.

\section{References}

Corrêa, R. S., de Oliveira, C. G., Vidotti, R. M., \& da Silva Souza, V., 2015. Regional-scale pressure shadowcontrolled mineralization in the Príncipe Orogenic Gold Deposit, Central Brazil. Ore Geology Reviews, vol. 71: 273-304.

Fuck, R. A., Dantas, E. L., Pimentel, M. M., Botelho, N. F., Armstrong, R., Laux, J. H., Junges, S.L., Soares, J.E. \& Praxedes, I. F. (2014). Paleoproterozoic crust-formation and reworking events in the Tocantins Province, central Brazil: a contribution for Atlantica supercontinent reconstruction. Precambrian Research, 244, 53-74.

Oliveira, C.G. 2012. Projeto Natividade. Instituto de Geociências. Universidade de Brasília.

Sousa, I. M. C. 2015. Geologia, geocronologia e geoquímica do embasamento granítico paleoproterozóico em natividade, Faixa Brasília Norte. Tese de mestrado. Instituto de Geociências, Universidade de Brasília.

Queiroz, J.P.C., 2001. Geologia e mineralização aurífera da área de Chapada-TO. Dissertação de mestrado (não publicada), Universidade Federal do Pará, 118 pp. 